\title{
O ensino de bioética: avaliaçáo discente por meio de fóruns de discussão na Internet
}

Cilene Rennó Junqueira ${ }^{1}$, Priscila Machado Tavares da Silva², Simone Rennó Junqueira ${ }^{3}$, Dalton Luiz de Paula Ramos ${ }^{4}$

Resumo: O estudo da bioética tem se desenvolvido preferencialmente com atividades presenciais em sala de aula. Sem pretender substituir este modelo presencial clássico, a disciplina de bioética, ministrada aos alunos do primeiro ano dos cursos diurno e noturno da Faculdade de Odontologia da Universidade de São Paulo (FOUSP), tem sido complementada com visitas supervisionadas às clínicas da Faculdade, bem como com estudos a distância em que se utiliza a plataforma Moodle. Neste estudo, foram avaliados os registros dos alunos feitos nos fóruns de discussão da plataforma Moodle em 2008, a fim de verificar qual a percepção deles acerca da proposta de visitas supervisionadas às atividades realizadas na clínica para seu processo de aprendizagem. Dos 100 alunos que postaram seus comentários nos fóruns de discussão da plataforma Moodle, 71 concordaram em participar da pesquisa. Trata-se de pesquisa qualitativa, realizada por meio da análise de conteúdo temática. A percepção dos alunos sobre essas atividades clínicas permite aos docentes aprimorá-la como estratégia pedagógica para as turmas futuras e servir de modelo para outras instituiçôes.

Palavras-chave: educação em odontologia, bioética, educação a distância

\section{Enseñanza de bioética: evaluación de los estudiantes a través de foros de discusión en Internet}

Resumen: El estudio de la bioética se ha desarrollado principalmente con actividades presenciales en clase. Sin pretender sustituir a este modelo clásico, la disciplina de bioética, enseńada a los estudiantes de primer ańo de los cursos diurnos y nocturnos en la Facultad de Odontología de la Universidad de Sáo Paulo (FOUSP), se ha complementado con visitas supervisadas a las clínicas de la Facultad, así como con estudios a distancia que utilizan la plataforma Moodle. En este estudio se evaluaron los registros de los estudiantes en los foros de discusión de la plataforma Moodle en 2008, para verificar su percepción acerca de la propuesta de visitas con supervisión a las actividades realizadas en la clínica durante su proceso de aprendizaje. De 100 estudiantes que publicaron sus comentarios en los foros de discusión, 71 aceptaron participar de la investigación. Se trata de un estudio cualitativo realizado a través del análisis de contenido temático. Las percepciones de los estudiantes acerca de estas actividades clínicas permiten a los profesores mejorarlas como estrategia pedagógica para clases futuras y para servir de modelo a otras instituciones.

Palabras clave: educación en odontología, bioética, educación a distancia

\section{Bioethics teaching: evaluation of students through internet discussion forums}

\begin{abstract}
Bioethics learning has mainly being developed in classroom activities. Without pretending to substitute this classical face to face model, bioethics discipline, taught to first year students at day and night courses in Dentistry Department of Sao Paulo University, has been complemented by supervised visits to Department Clinics, as well as on line studies using Moodle platform. In this study students' records of discussion forums in Moodle platform in 2008 were evaluated to verify their perception about the proposal of supervised visits to clinical practice during their learning process. 71 of 100 students who published comments in discussion forums accepted to participate in the study. This is a qualitative study carried out by thematic content analysis. Students' perceptions about clinical practice allow professors to enhance their practice as pedagogical strategy for future classes and this may serve as model for other institutions.
\end{abstract}

Key words: oral health education, bioethics, distance learning

\footnotetext{
${ }^{1}$ Doutora em Ciências Odontológicas, área de concentração Odontologia Social, pela Faculdade de Odontologia da Universidade de São Paulo, Brasil

Correspondência: cilene_junqueira@uol.com.br

${ }^{2}$ Aluna de graduação de Odontologia, bolsista de iniciação científica do Programa "Ensinar com Pesquisa” da Pró-reitoria de Graduação da Universidade de Sáo Paulo, Brasil

${ }^{3}$ Professora Doutora do Departamento de Odontologia Social da Faculdade de Odontologia da Universidade de São Paulo, Brasil

${ }^{4}$ Professor Titular do Departamento de Odontologia Social da Faculdade de Odontologia da Universidade de São Paulo, Brasil
} 


\section{Introduçáo}

A atenção devida ao paciente inserido no contexto do ensino e ao aluno, no âmbito da formaçáo em Odontologia, presume a necessidade de reconhecer as pessoas como seres únicos e constituídos de uma totalidade de aspectos - biológicos, sociais, psíquicos e espirituais-, enfim como pessoas dotadas de uma dignidade que torna cada uma merecedora de atenção.

Devem-se valorizar situaçóes que promovam a dignidade das pessoas no tocante à privacidade, à consideração pelas emoçóes, à demonstração de respeito(1-4).

O conceito de dignidade ao qual nos referimos neste trabalho é o de uma dignidade ontológica, no qual se reconhece uma dignidade "intrínseca" em cada pessoa (5-7).

$\mathrm{Na}$ esfera da saúde, quando os pacientes sentem que sua dignidade está sendo respeitada, eles aderem melhor ao tratamento e referem maior satisfação; é preciso, para tanto, mais do que de respeito por sua autonomia(8).

$\mathrm{Na}$ esfera da formação superior em saúde no Brasil, a preocupação com a dignidade das pessoas é expressa nas Diretrizes Curriculares Nacionais $(\mathrm{DCN})(9)$ - que balizam o ensino de todos os cursos superiores na área da saúde- dentre outros aspectos, pela necessidade de se incorporarem conteúdos de ética/bioética em seus currículos.

Ademais, as DCN preveem que o aluno deva ser estimulado a "aprender a aprender, a aprender a viver junto, a aprender a ser" que se configuram nos pilares da educação(10).

Contudo, o modelo tradicional de ensino de pautado na transmissão de informaçóes (consequência dos Relatórios Flexner, 1910 e Gies, 1926) não é capaz de permitir atingir plenamente esse fim. Dessa forma, os projetos pedagógicos devem ser aprimorados de forma a possibilitar que esses objetivos sejam atingidos. Por isso, tem sido estimulada a reorientação dos currículos dos cursos da área da saúde(11).
Desde 2004 foi inserida a disciplina de bioética no curso de graduaçáa da Faculdade de Odontologia da Universidade de São Paulo (FOUSP). Oferecida aos alunos do primeiro ano, tem como objetivo o exercício para o reconhecimento de conflitos éticos, a análise crítica de suas implicaçóes, o uso de senso de responsabilidade e a obrigação moral ao tomar decisóes relacionadas à vida humana e à natureza.

A aproximação da teoria com a prática, seja na forma de estágios supervisionados, seja na forma de atividades práticas realizadas por todas as disciplinas constitui estratégia pedagógica importante na busca desses objetivos.

Dada a crescente utilização dos novos recursos de mídia na educação a distancia, que tem sido estimulada, mundial e nacionalmente e que contribui para que as pessoas compartilhem informaçóes e suas experiências(12), a plataforma Moodle foi incorporada por esta disciplina de bioética com o intuito de contribuir para o processo ensino-aprendizagem dos graduandos. Moodle corresponde a um ambiente virtual de aprendizagem. Esse sistema está sendo utilizado por diversas disciplinas da graduação e da pós-graduação na instituição.

Porém, para que a educação virtual seja efetiva, é necessário avaliar as propostas pedagógicas, atentar-se para o potencial e limitaçôes desta tecnologia, manter uma integraçáo entre alunos e tutores com o ambiente e analisar os resultados obtidos(13).

Assim, neste estudo, pretenderam-se avaliar qualitativamente, por meio de análise de conteúdo temática(14), os comentários dos alunos, registrados nos fóruns de discussão da plataforma Moo$d l e$, a fim de identificar a percepção dos alunos sobre as atividades clínicas desenvolvidas para promover o aprendizado em bioética.

\section{Material e método}

O estudo foi iniciado após a aprovação do Comi- 
tê de Ética em Pesquisa da Faculdade de Odontologia da USP - São Paulo (parecer 27/2009).

O conteúdo da disciplina de bioética, disponibilizado no Moodle, foi configurado de forma a que cada assunto representasse um tópico e incluiu as aulas ministradas na disciplina e os textos apresentados aos alunos nas aulas práticas, seminários e discussões de casos. Além desses conteúdos, foram disponibilizadas ferramentas interativas e de comunicação como fóruns, ferramentas de avaliação, disponibilização de notas das avaliações, cronograma de aulas.

Foi solicitado aos alunos que registrassem a sua percepção sobre a visita supervisionada à Clínica, em fóruns de discussão criados na plataforma Moodle, do qual participavam todos os alunos e professores. Como parte central da atividade, foi sugerido que registrassem suas impressões sobre as relações interpessoais que observaram, e não sobre os procedimentos clínicos que estavam sendo realizados. Esses registros foram distribuídos a todos os alunos e professores do curso pelo próprio sistema, via e-mail.

Para os fins da presente pesquisa, os alunos que haviam publicado seus relatos no fórum de discussão na Plataforma Moodle (100 alunos) receberam o Termo de Consentimento Livre e Esclarecido. Foram analisados os relatos dos alunos que concordaram em participar da pesquisa (71 alunos).

Para proceder à análise dos dados, utilizou-se a metodologia qualitativa, visto que se pretendeu compreender o significado dos fenômenos (e não quantificá-los), e porque essa metodologia permite o estudo de valores, comportamentos e crenças(15).

Como estratégia metodológica para a análise qualitativa dos dados, optou-se pela análise de conteúdo temática $(14,16)$, por permitir a compreensão da experiência dos alunos acerca da atividade desenvolvida.

Optou-se por utilizar os dados dos fóruns de discussão da Internet, pois estes permitem às pessoas manifestarem sua opiniāo sobre questôes recentes, no momento em que ocorrem(17).

A participação no fórum não era uma atividade obrigatória da disciplina e para garantir que os participantes náo fossem identificados, foram atribuídos uma letra e um número a cada um deles (A1, A2, A3 e assim sucessivamente).

Após realizar a leitura do material, os comentários dos alunos foram categorizados e divididos em temas. As categorias foram definidas e revisadas por todos os autores, a fim de agrupá-las para atingir a concordância entre os autores sobre o significado dos temas e assim validar os resultados.

\section{Resultados e discussão}

Da análise dos dados, emergiram os seguintes temas que foram analisados: 1- a relação profissional-paciente; 2- a postura profissional; 3- a avaliaçấo da atividade.

Ressaltamos que os alunos, sujeitos desta pesquisa, tiveram a liberdade de expressar sua opinião acerca da atividade realizada de visita à clínica —nos fóruns de discussão. Entretanto eles foram orientados pelos tutores a expressarem o que vivenciaram na clínica, espaço em que os pacientes estavam recebendo atendimento clínico odontológico como parte do aprendizado de outros alunos. Não esperávamos que eles observassem os procedimentos clínicos realizados, mas a relação estabelecida entre as diversas pessoas —alunos, professores, pacientes e funcionários.

A incorporação dos conteúdos de bioética nos currículos dos cursos de Odontologia atende aos pressupostos das DCN (Art. 30), quando reforça que os egressos devem ter uma formação generalista, humanista, crítica e reflexiva, para atuar em todos os níveis de atençáo à saúde, com base no rigor técnico e científico. Além de ter de estar capacitado ao exercício de atividades referentes à saúde bucal da população, pautado em princípios éticos, legais e na compreensão da realidade social, cultural e econômica do seu meio, dirigindo sua atuação para a transformação da realidade em 
benefício da sociedade(9).

O ensino da bioética tem se desenvolvido preferencialmente com atividades teóricas em sala de aula. Sem pretender substituir este modelo teórico e presencial clássico, a disciplina de bioética, ministrada aos alunos do primeiro ano dos cursos diurno e noturno da Faculdade de Odontologia da Universidade de São Paulo (FOUSP), tem sido complementada com estudos a distância com a utilização da plataforma Moodle.

\section{A relaçáo profissional-paciente}

A relação profissional-paciente é um dos temas mais importantes estudado pela disciplina de bioética do curso avaliado, emergiu nos discursos dos alunos e se constituiu em um tema.

Antes da visita supervisionada à clínica, foi sugerido aos alunos que observassem a relação entre o aluno, o professor e o paciente na clínica. Alguns dos relatos confirmam que a visita, já no primeiro ano da graduação, pode favorecer que o aluno tenha uma visão "ampliada" do paciente, e o enxergue como uma pessoa única dotada de múltiplas dimensóes e não como um conjunto de dentes ou uma boca a ser tratada.

Seguem alguns relatos postados no fórum da internet que confirmam essa compreensão:

"Cada paciente é único, a relação que o cirurgião dentista tem com o seu paciente é única" (A4).

"Senti o quanto é importante nos aproximarmos dos pacientes pra estabelecer uma relação mais de igual pra igual" (A33).

"Os pacientes têm necessidades diferentes e perfis diferentes!" (A48).

"Então eu me dirigi a ela segurando sua mão. Fiquei MUITO contente com essa interação" (A53) (sobre o fato de uma aluna se dispor a acalmar a paciente para que lhe fosse aplicada a anestesia, com o simples ato de segurar nas máos da paciente).

"Mesmo não tendo características semelhantes aos pacientes devemos, como profissionais, buscar entender sua realidade e dar o nosso melhor para suprir e até superar as suas expectativas" (A62).
Os alunos destacaram a necessidade de reconhecer o outro, de respeitar a dignidade do paciente, que deve ser atendido respeitando-se todas as suas dimensões(18).

Os alunos relataram que o ambulatório que contradiz a regra é o serviço de emergência. Nesse setor, são acolhidos todos os pacientes que referem algum grau de dor de origem odontológica. Após o atendimento emergencial, os pacientes são encaminhados para o setor de Triagem para serem dirigidos, na medida da pouca disponibilidade de vagas, para as diferentes clínicas da faculdade.

Sobre esse serviço, os alunos relataram:

"Percebia-se um distanciamento do paciente com o dentista, por não se ter um acompanhamento do tratamento" (A14).

"Na emergência o que percebemos é que o objetivo não é tanto o paciente, mas sim a quantidade deles que têm seus problemas, suas dores, resolvidas em pouco tempo" (A38).

"Na emergência podemos perceber que não há tempo para um conhecimento muito amplo entre dentista e paciente" (A39).

Diante da exiguidade de tempo para a realização do atendimento clínico emergencial, é natural os alunos perceberem que o profissional tenha dificuldade de estabelecer uma relação empática com o paciente.

\section{A postura profissional}

Outro tema bastante frequente nos discursos dos alunos foi a constataçáo de que o "uniforme" branco pode dificultar a aproximaçáo com o paciente:

"A vestimenta branca intimida as pessoas, todos os pacientes ao passarem perto da gente abaixava a cabeça” (A8).

"A roupa branca muda o jeito com que as pessoas nos olham criando assim uma barreira física!" (A69).

Em alguns casos esse uniforme pode facilitar a relação com o paciente, pois identifica o aluno como "representante da Instituição" que é respei- 
tada como polo de boa formação profissional:

"Provavelmente a roupa branca e o avental que eu estava utilizando representaram um motivo de respeito. Um deles até me perguntou se era eu quem ia arrancar o dente dele!” (A5).

"Por estarmos com avental da faculdade eles já nos tratavam como doutores e com muito respeito" (A29).

Ao expressarem a facilidade e/ou dificuldade de aproximação com o paciente em razão da postura profissional expressa pelo uniforme (roupa branca e avental), os alunos identificaram que o contexto (social ou cultural) influencia a relação, seja positiva ou negativamente.

Ao referirem que o paciente "abaixava a cabeça", ou que a roupa branca "muda o jeito com que as pessoas olham" os alunos, eles manifestam que culturalmente há uma diferença na relação que se estabelece entre as pessoas.

\section{A avaliaçáo da atividade}

A atividade de visita supervisionada à clínica realizada como estratégia pedagógica adotada pela disciplina de bioética foi bem avaliada pelos alunos que destacaram que a antecipaçáo do contato com os pacientes, com o dia-a-dia da clínica, permitiu compreender melhor o conteúdo teórico ministrado pela disciplina, no que se refere ao relacionamento profissional-paciente e aos conceitos teóricos ministrados pela disciplina de bioética.

"Achei a atividade muito interessante gostei muito dessa maneira nova de enxergar e observar a clínica" (A2).

"A experiência foi muito rica, pudemos aprender bastante com a observação do espaço clínico e humano" (A26).

"Conseguimos colocar em prática o que nos foi passado na sala de aula" (A50).

"Achei muito válida essa experiência, pois não tinha nem um pouco de noção de como era o funcionamento, o perfil da clínica, dos pacientes, dos atendentes e dos alunos lá" (A62).

"Enxergamos os fatos com outros olhos" (A68).
Com a aquisição de novos conhecimentos científicos relativos à área da saúde, há a tendência de as relaçôes entre as pessoas envolvidas perderem espaço, pois as atençôes desviam-se para a aplicação das novas tecnologias (ou biotecnologias) que passam a ser o objeto da confiança.

Para Freitas et al.(19), os formandos de Odontologia não estão preparados moralmente para o mercado de trabalho, "tratando os interesses do indivíduo de forma indiferenciada, sem relativizar contextos ou situaçôes".

Dessa forma, para resgatar o sentido das relaçôes humanas, há necessidade de discussão sobre os novos desafios bioéticos que surgem na sociedade e que, aos futuros profissionais, seja dada a oportunidade — e o incentivo- para que possam não apenas vivenciar o contato com a pessoa do paciente, mas também que possam exercitar um juízo crítico sobre essas experiências vivenciadas.

Para isso, é de fundamental importância a opinião da equipe de profissionais da instituição de saúde, a cooperação de vários profissionais na assistência, a identificação dos pacientes através de seus nomes e o autoconhecimento. A humanização está diretamente relacionada às condiçóes de trabalho do profissional. E os profissionais e os responsáveis pelo gerenciamento dos serviços de saúde são corresponsáveis pela humanização do atendimento(20).

O ensino da bioética na graduação possibilita a reflexão dos alunos sobre vários temas que se relacionam ao impacto das novas tecnologias sobre a vida e deve partir da exposição de valores e princípios que servem como "instrumentos" para o pensar criticamente, para a compreensão e a tomada de decisóes diante de desafios éticos.

É importante que o aluno compreenda e incorpore o pensamento de que a harmonia do relacionamento pessoal entre o profissional e o paciente está alicerçada principalmente na confiança mútua e que isso é resultado de um relacionamento pautado em princípios éticos.

O ensino da bioética deve ser ampliado para a 
prática, para onde e como nós experimentamos os desafios éticos(21).

Enfim, mais importante do que a incorporação de uma disciplina de bioética nos cursos, é o resgate da reflexáo ética portodos os que se dedicam à tarefa de ensinar, sobretudo pelo exemplo(22), visto que as atitudes éticas devem ser exercitadas como um hábito, que se tornará tanto mais fácil quanto mais for praticado.

Por isso, a responsabilidade pelo ensino da bioética não deve ser atribuição exclusiva dos professores desta disciplina, mas de toda a comunidade docente da Instituição.

Outros métodos de ensino em bioética podem ser empregados como discussão de casos, no qual os alunos aplicam o que foi aprendido(23), ou a inclusão da Ética com uma abordagem transversal, na qual as diferentes disciplinas da graduação planejam atividades para o desenvolvimento moral, contando com um planejamento desde o início até o fim do curso(24).

Os docentes e pesquisadores necessitam estar treinados para o reconhecimento de conflitos éticos, para a análise crítica de suas implicaçóes, para o uso de senso de responsabilidade e para a obrigação moral ao tomar decisões relacionadas à vida humana e à natureza.

O ensino de bioética deve proporcionar discussões sobre dilemas éticos vividos pelos alunos no cotidiano e os professores devem utilizar a bioética para acompanhar nos alunos em seus anos de formação $(25)$.

No Brasil, 55\% dos cursos de pós-graduação em Odontologia (stricto senso) tinham uma disciplina de bioética em seus currículos, e 54\% incorporavam conteúdos de bioética em disciplinas de seus currículos(26).

Nas Faculdades de Odontologia do Estado de São Paulo, o curso de bioética é aplicado na minoria das faculdades e normalmente é oferecido na segunda metade da graduação, o que pode prejudicar os conteúdos éticos e priorizar as discipli- nas clínicas. É fundamental que ao longo de sua graduação o estudante seja sensibilizado com reflexóes éticas na relação com o paciente, a fim de desenvolver hábitos responsáveis e tomar decisões de forma ética(27).

Essa atividade permitiu que os alunos observassem o que está "além do procedimento clínico", como o comportamento dos estudantes que ali estavam realizando o atendimento clínico e o dos pacientes que aguardavam na sala de espera para serem atendidos.

As relações humanas devem estar interligadas com a confiança mútua, atentando para a pessoa como um todo, o que gera tal credibilidade observada por parte dos alunos.

\section{Consideraçóes finais}

As experiências relatadas contribuem para o conhecimento e a aplicaçáo da humanizaçáo no cotidiano profissional; o aluno deve ser capaz de "relativizar contextos ou situaçóes", fato que os torna moralmente preparados para atuaçáo profissional (19). O ingressante, ao ter estas vivências, desperta sua capacidade de refletir sobre seu comportamento ao longo de sua carreira.

A reflexão permite que as pessoas façam julgamentos diante de situações complexas e ambíguas. As estratégias didáticas e os métodos de avaliação devem ser alterados para favorecer o desenvolvimento do pensamento crítico que preparará o aluno para resolver, no futuro, os problemas reais dos pacientes (28).

Se as estratégias pedagógicas se restringirem à transmissão de informações e ao treinamento de habilidades, o pensamento crítico não será plenamente desenvolvido.

A humanização no atendimento é responsabilidade dos profissionais envolvidos na assistência ao paciente. Como citado por um dos alunos, é necessário "dar mais atenção aos pacientes que aos procedimentos". Dessa maneira o profissional perceberá o paciente como um ser completo e 
não apenas sua condição de enfermidade ou dor, o que está de acordo com Hoga(20).

Esta maneira de estudar a clínica, na qual não se pretendeu ensinar um procedimento clínico, mas sim que os alunos atentassem à pessoa humana, foi avaliada positivamente pelos próprios alunos da disciplina, e categorizada como "a avaliação da atividade".

Para muitos alunos, a atividade proporcionou uma primeira passagem pela clínica da FOUSP, o que supriu a curiosidade sobre seu funcionamento logo no primeiro ano do curso e proporcionou um "primeiro contato com pacientes" (A58).

Outros alunos já estagiavam nas clínicas da FOUSP, porém foi concedida a eles, uma maneira de "enxerga(r) os fatos com outros olhos" (A68).

Enfim, o ensino de bioética deve ocorrer com constantes discussóes de casos do cotidiano da carreira profissional e problematizaçóes ao longo da formação do estudante(23-25).

De acordo com os resultados desta pesquisa, pode-se inferir que a atividade de visita às clínicas configurou-se como estratégia pedagógica importante para o ensino da bioética, sobretudo da re- lação profissional-paciente, no momento em que ocorrem, ou seja, durante o atendimento realizado nas clínicas da Instituição.

Além disso, os fóruns de discussão permitiram que a percepção dos alunos sobre as visitas fosse compartilhada entre eles e os docentes, favorecendo e enriquecendo as discussóes.

Por fim, a ferramenta do ensino a distância mostrou-se útil como apoio para o aprendizado do aluno em bioética. Sobretudo porque permitiu que as atividades tivessem continuidade para além do momento da visita supervisionada, com desdobramento representado pela retomada da experiência quando da elaboração do comentário pessoal, como também na participação no fórum de discussão.

Apesar de o estudo descrever uma experiência pedagógica pontual, os resultados indicam que esta pode representar um novo horizonte para o ensino da bioética com a vivência de situaçôes reais e a extrapolação das discussóes nos fóruns virtuais. Entretanto, este estudo não pretendeu esgotar o assunto e novas investigaçóes que apontem outras estratégias pedagógicas deverão ser realizadas para aprimorar o ensino da bioética.

\section{Referências}

1. Shotton L, Seedhouse D. Practical dignity in caring. Nurs Ethics 1998; 5(3): 246-55.

2. Walsh K, Kowanko I. Nurses' and patients' perceptions of dignity. Int J Nurs Pract 2002; 8(3): 143-151.

3. Griffin-Heslin VL. An analysis of the concept dignity. Accid Emerg Nurs 2005; 13(4): 251-257.

4. Matiti MR, Trorey GM. Patients' expectations of the maintenance of their dignity. J Clin Nurs 2008; 17(20): 2709-2717.

5. Organização das Nações Unidas (ONU). Declaração Universal dos Direitos Humanos. Genebra: ONU; 1948.

6. Palazzani L. La fundamentación personalista en Bioética. Cuadernos de Bioética 1993; 14(2): 4854.

7. Sgreccia E. Manuale di Bioetica. Vol. I - Fondamenti de etica biomedica. Milano: Vita e Pensiero; 2003.

8. Beach MC, Sugarman J, Johnson RL, Arbelaez JJ, Duggan PS, Cooper LA. Do patients treated with dignity report higher satisfaction, adherence, and receipt of preventive care? Ann Fam Med 2005; 3(4): 331-338. 
9. Brasil. Ministério da Saúde. Ministério da Educação. Resolução CNE/CNS 3/2002. Diretrizes Curriculares Nacionais do Curso de Odontologia. Diário Oficial da União, Brasília, 4 de março de 2002. Seção 1, p.10, Brasília, 2002.

10. Delors J. Educação: um tesouro a descobrir. São Paulo: Cortez, UNESCO, MEC; 1999.

11. Brasil. Ministério da Saúde. Ministério da Educação. Secretaria de Gestão do Trabalho e da Educação na Saúde. Programa Nacional de Reorientação da Formação Profissional em Saúde - Pró-saúde. Brasília; 2005. Disponível em http://www.saude.gov.br/sgtes. Acesso em 12 de abril de 2007.

12. Macedo MCS, Antoniazzi JH. The benefits and newly required practices brought about by innovations in the communication between professionals. Braz Oral Res 2009; 23(2): 99-100.

13. Laguardia J, Portela MC, Vasconcellos MM. Avaliação em ambientes virtuais de aprendizagem. Educação e Pesquisa 2007; 33(3): 513-530.

14. Bardin L. Análise de conteúdo. Lisboa: Edições 70; 2009.

15. Richards L, Morse JM. Readme first for a user's guide to qualitative methods. Thousand Oaks: Sage Publications; 2007.

16. Minayo MC. O desafio do conhecimento: pesquisa qualitativa em saúde. $11^{a}$ ed. São Paulo: Hucitec, 2008.

17. Seale C, Charteris-Black J, MacFarlane A, McPherson A. Interviews and internet forums: a comparison of two sources of qualitative data. Qual Health Res 2010; 20(5): 595-606.

18. Junqueira CR, Ramos DLP. Aspectos éticos da percepção de pacientes em atendimento odontológico. Rev Bras Cien Saúde 2007; 11(1): 95-102.

19. Freitas SFT, Kovaleski DF, Boing AF. Desenvolvimento moral em formandos de um curso de odontologia: uma avaliação construtivista. Ciênc Saúde Coletiva 2005; 10(2): 453-462.

20. Hoga LAK. A dimensão subjetiva do profissional na humanização da assistência à saúde: uma reflexão. Rev Escola de Enfermagem da USP 2004; 38(1): 13-20.

21. Austin W, Park C, Goble E. From interdisciplinary to transdisciplinary research: a case study. Qual Health Res 2008; 18(4): 557-564.

22. Léon Correa FJ. Enseñar bioética: cómo trasmitir conocimientos, actitudes y valores. Acta Bioethica 2008; 14(1): 11-18.

23. Rego S, Gomes AP, Siqueira-Batista R. Bioética e humanização como temas transversais na formação médica. Rev Bras Educ Med 2008; 32(4): 482-491.

24. Ferreira HM, Ramos LH. Diretrizes curriculares para o ensino da ética na graduação em enfermagem. Acta Paul Enferm 2006; 19(3): 328-331.

25. Blasco PG, De Otálora MSD, Pastushenko J, Trota RA. ¿Cómo enseñar bioética en el pregrado? Reflexiones sobre experiencias docentes. Aten Primaria 2009; 41(2): 103-108.

26. Aires CP, Hugo FN, Rosalen PL, Marcondes FK. Teaching of Bioethics in dental graduate programs in Brazil. Braz Oral Res 2006; 20(4): 285-289.

27. Musse JO, Boing AF, Martino FS, Silva RHA, Vaccarezza GF, Ramos DLP. O Ensino da bioética nos cursos de graduação em odontologia do estado de São Paulo. Arq Ciênc Saúde 2007; 14(1): 13-16.

28. Boyd LD. Reflections on clinical practice by first-year dental students: a qualitative study. J Dent Educ 2002; 66(6): 710-720.

Recebido: 16 de fevereiro de 2011

Aceito: 27 de junho de 2011 